\title{
A retrospective evaluation of fondaparinux for confirmed or suspected heparin-induced thrombocytopenia in left-ventricular-assist device patients
}

Scott T Benken ${ }^{1 *}$, Nicholas Tillman², Suhuir Dajani ${ }^{2}$, Aesha Shah ${ }^{2}$ and Toby Thomas ${ }^{2}$

\begin{abstract}
Background: Thrombotic events are a common complication of left ventricular assist device placement and warrant prophylactic anticoagulation. Heparin is the most common anticoagulant used for prophylaxis of thrombotic events in left ventricular assist device patients as a transition to oral anticoagulants but carries the risk of heparin-induced thrombocytopenia. Limited data is available for the treatment of heparin-induced thrombocytopenia in this patient population. We report an evaluation of 8 left ventricular assist device patients with suspected or confirmed HIT started on fondaparinux at the time of heparin-induced platelet-factor- 4 antibody positivity.

Methods: Adult patients were reported if they were heparin-induced platelet antibody positive, tested via enzyme-linked immunusorbent assay, post-operative after left-ventricular assist device, and were initiated on fondaparinux at the time of heparin-induced platelet antibody positivity. Waiver of informed consent was granted from the institutional review board. Baseline demographics, clinical course of HIT, safety and efficacy variables were collected.

Results: Eight patients receiving fondaparinux were identified and included in this report. The patient group was on average 49 years old, weighing $95 \mathrm{~kg}$, with calculated BMI 28.8 and consisted primarily of Caucasian males. Three patients developed new thromboses after initiation of fondaparinux for heparin-induced thrombocytopenia. Only one patient had a major bleeding event of an overt bleed after initiation of fondaparinux therapy.

Conclusions: Given the lack of major bleeding in this evaluation, fondaparinux could be a potentially safe treatment option for left ventricular assist device patients that are heparin-induced platelet antibody positive pending confirmatory testing results. Given the development of new thromboses in 3 of 8 patients, concern exists about the efficacy of fondaparinux in this patient population. Significant limitations exist regarding these conclusions in this evaluation. Controlled, systematic evaluations are necessary to delineate safety and efficacy of fondaparinux for heparin-induced thrombocytopenia in this population.
\end{abstract}

Keywords: Left-ventricular-assist device, Heparin-induced thrombocytopenia, Thrombosis, Bleeding, Fondaparinux, Anticoagulation

\footnotetext{
* Correspondence: scott.benken@uchospitals.edu

'Department of Pharmacy, The University of Chicago Medicine, 5841 S.

Maryland Ave. TE026, MC0010, Chicago, IL 60637, USA

Full list of author information is available at the end of the article
} 


\section{Background}

The management of patients with heart failure has progressed in recent years due to the increased utilization of ventricular assist devices (VADs), including left ventricular assist devices (LVADs) [1,2]. According to the Centers for Disease Control and Prevention, an estimated 5.8 million people in the United States have heart failure and 550,000 are newly diagnosed with end stage heart failure each year [1]. Because of this burden, there has been an increased utilization of LVADs [2]. Data with contemporary LVAD's (Heartware and Heartmate II) suggest an increased 1-year survival compared to historical data of medical therapy and it is estimated that $>3000$ LVADs are implanted worldwide each year [1-5].

Although LVADs are potentially lifesaving and life extending, there are serious complications that arise postoperatively; most prominently bleeding and thrombosis $[6,7]$. Bleeding complications often lead to re-operation and occur more frequently than in other cardiac surgery and medical patient populations [8-10]. Thrombotic events in VAD patients occur at a reported incidence ranging up to $26 \%$ and because of this, all LVAD patients will be transitioned to long-term anticoagulation unless contraindicated [11]. Per consensus guidelines, it is recommended that LVAD patients be bridged with intravenous heparin to warfarin beginning as early as postoperative day 1 until therapeutic international normalized ratio (INR) is reached [12].

Given the common use of heparin, LVAD patients have an increased incidence of heparin-induced thrombocytopenia (HIT). The incidence approaches $\sim 10 \%$, which is twice as frequent as other post-surgical populations [13]. Due to the already high disease-related-rates of thromboses and significantly higher risk of bleeding complications at baseline, anticoagulation management for HIT in LVAD patients presents a clinical challenge.

Alternative anticoagulants that can been considered for the initial treatment of HIT patients, include selective factor Xa inhibitors (danaparoid and fondaparinux) and direct thrombin inhibitors (DTI's: argatroban, lepirudin, desirudin, and bivalirudin) [14]. In the United States, the commonly utilized therapies for HIT include argatroban and bivalirudin (approved for HIT during percutaneous coronary intervention). Anecdotally, fondaparinux is utilized for this indication. One study found success while utilizing argatroban to manage HIT in VAD patients without an increased risk of bleeding [15]. Bivalirudin has been used during cardiac surgery in patients with a history of HIT, but its use in the treatment of HIT in LVAD patients has been shown only in case reports [16-18]. Fondaparinux has only one published case specifically in VAD patients (biventricular VAD only), no published cases with LVADs, but experience is growing in cardiac surgery patients [19-21].
Fondaparinux has pharmacologic characteristics that would make it desirable for the use of HIT in this population [22]. It is rapidly and completely absorbed after subcutaneous administration requiring no intravenous access. It also is distributed mainly in the blood which leads to predictable activity that should not be affected by changing volume of distribution in hospitalized patients. Further, it has peak anti-Xa activity occurring fairly rapidly in approximately $2-3$ hours, requires no biotransformation for activity or elimination, and has no required monitoring parameters. Because of this, we investigated our institutional experience utilizing fondaparinux in LVAD patients with suspected or confirmed HIT.

\section{Methods}

This was a retrospective, single-center, tertiary care, academic medical center evaluation. It was approved by the Northwestern Medicine Institutional Review Board (IRB) and due to the retrospective nature of the evaluation, waiver of informed consent was obtained. Adult patients ( $>18$ years) who tested positive (optical density [OD $>0.4]$ ) by enzyme-linked immunosorbent assay (ELISA) for the heparin-induced platelet antibody (HIPA) were identified and included. A query was done of these patients' electronic medical records (EMR) from December 2008 to January 2012 for patients who received a LVAD (Heartware, Heartmate or Heartmate II). These lists were then cross-referenced to identify those LVAD patients who were HIPA positive and received fondaparinux during the evaluation period.

Major bleeding was defined as fatal bleeding, bleeding in a critical organ (retroperitoneal, intracranial, intraocular, etc.), deep hematoma, overt bleeding (an acute $2 \mathrm{~g} / \mathrm{dl}$ or greater decrease in hemoglobin level), or bleeding leading to the transfusion of at least 2 consecutive units of packed red cells (PRBCs) within a 24 hour period. Thrombosis was detected by clinical suspicion coupled with standard diagnostic testing. For deep vein thrombosis, diagnosis required positive doppler ultrasonography; for pulmonary embolism, computed tomography was used to confirm diagnosis; for pump thrombosis, elevations of lactate dehydrogenase, decrease in haptoglobin, and surgical attending confirmation were required. Of note, surveillance diagnostic detection was not performed during the evaluation period. New thrombosis after anticoagulation was defined as the development of a new thrombosis after HIT diagnosis until 3-month follow-up. Isolated HIT was described as HIT with only platelet reduction at time of diagnosis [23]. Heparin induced thrombocytopenia and thrombotic syndrome was described as HIT associated with concomitant thrombosis [23]. Selection of fondaparinux for anticoagulation was determined by the treating providers at the time of treatment and given the retrospective nature of this evaluation, reasons for selection 
were not elucidated. It is important to note, that all Heartware patients were started on aspirin $325 \mathrm{mg}$ daily and Heartmate II patients on aspirin $81 \mathrm{mg}$ daily according to hospital protocol. Data is presented in medians and interquartile ranges (IQR) unless otherwise specified.

\section{Results}

Eight patients were identified with a positive HIPA test in the post-operative setting status post LVAD implantation that received fondaparinux (Table 1). The patient group had a median age of 49 years old $(7.8 \mathrm{y} / \mathrm{o})$, weighing $95 \mathrm{~kg}$ $(21.2 \mathrm{~kg})$, with calculated BMI $28.8 \mathrm{~kg} / \mathrm{m}^{2}\left(4.3 \mathrm{~kg} / \mathrm{m}^{2}\right)$ and consisted primarily of Caucasian (87.5\%) males (75\%). Only one (12.5\%) patient had a history of VTE prior to admission, no patients had a history of diagnosed bleeding disorders, and two (25\%) patients had a history of chronic kidney disease (CKD; defined as estimated GFR $<60 \mathrm{~mL} / \mathrm{min} / 1.73 \mathrm{~m}^{2}$ for $\geq 3$ months). Six (75\%) patients received Heartmate II devices and 2 (25\%) received Heartware LVADs.

The admission median platelet count was $185 \mathrm{k} / \mathrm{ul}$ $(70 \mathrm{k} / \mathrm{ul})$ with a median decrease of $48.4 \%(30.7 \%)$ to a temporal (nearest platelet count within $24 \mathrm{hr}$ to the HIT + antibody) platelet nadir of $57 \mathrm{k} / \mathrm{ul}(52 \mathrm{k} / \mathrm{ul})$. The HIT antibody was drawn 5 days (57.8 days) after admission to the intensive care unit (ICU) from the operating room. The 4-T pre-test probability of HIT demonstrated: 4. (50\%) low probability, 3 (37.5\%) intermediate probability, and $1(12.5 \%)$ high probability [24]. The median HIPA OD via ELISA was 1.11 (0.63). Five of the eight (62.5\%) patients received hematology consults to assist in the management of HIT. Confirmatory testing with the serotonin release assay (SRA) was sent on four (50\%) patients (send-out laboratory test at our institution) and one returned as positive. Of note, the one patient with a positive SRA also had an ELISA OD of 3.15 and high probability on 4 T scoring.

At time of diagnosis, 3 (37.5\%) patients had heparininduced thrombotic-thrombocytopenic syndrome (HITTS) and $5(62.5 \%)$ with isolated HIT (iHIT). The patients that presented with HITTS had the following thromboses: 1 patient - DVT alone, 1 patient - DVT, PE, and probable acute ischemic stroke, and 1 patient - PE alone. Patients were started on fondaparinux at the time of HIPA positivity at a median dose of $5 \mathrm{mg}$ (Table 2). The median duration of fondaparinux treatment was 4.5 days ( 8 days) with 6 of $8(75 \%)$ patients being transitioned to warfarin before discharge (2 patients discharged on fondaparinux). All patients discharged on warfarin were discharged with an INR within goal range of 2-3.

Three (37.5\%) patients developed a new thrombotic event after the diagnosis of HIT despite the initiation of fondaparinux transitioned to therapeutic warfarin prior to discharge (1 patient - PE, 1 patient - LVAD thrombosis, 1 patient - DVT). It was not routine practice during the evaluation period to perform surveillance diagnostic testing unless clinical suspicion was raised and thus thromboses were only diagnosed after clinical concern developed. All

Table 1 HIT characteristics

\begin{tabular}{|c|c|c|c|c|c|c|c|c|c|c|}
\hline Patient & $\begin{array}{l}\text { Type of } \\
\text { LVAD }\end{array}$ & $\begin{array}{c}\text { Admission } \\
\text { Plt (K/uL) }\end{array}$ & $\begin{array}{l}\text { Temporal } \\
\text { Plt nadir } \\
(\mathrm{K} / \mathrm{uL})^{*}\end{array}$ & $\begin{array}{c}\text { ELISA } \\
\text { OD }\end{array}$ & $\begin{array}{c}\text { 4-T } \\
\text { probability** }\end{array}$ & $\begin{array}{l}\text { Heme-onc } \\
\text { consult }\end{array}$ & $\mathrm{SRA}^{* * *}$ & HITTS $^{\top}$ & $\begin{array}{l}\text { Time of heparin } \\
\text { exposure prior } \\
\text { to LVAD surgery } \\
\text { (days) }\end{array}$ & $\begin{array}{c}\text { Time between } \\
\text { heparin exposure } \\
\text { and HIT Ab + (days) }\end{array}$ \\
\hline 1 & Heartmate II & 157 & 127 & 0.54 & Low & $Y$ & $(-)$ & No & 12 & 19 \\
\hline 2 & Heartmate II & 120 & 80 & 0.82 & Intermed & $\mathrm{N}$ & $\mathrm{n} / \mathrm{a}$ & No & $\mathrm{n} / \mathrm{a}$ & $0^{t}$ \\
\hline 3 & Heartware & 203 & 99 & 0.44 & Intermed & Y & $\mathrm{n} / \mathrm{a}$ & DVT & 17 & 21 \\
\hline 4 & Heartware & 217 & 118 & 0.64 & Low & $\mathrm{N}$ & $(-)$ & No & 6 & 10 \\
\hline 5 & Heartmate II & 166 & 102 & 0.63 & Low & $\mathrm{N}$ & $\mathrm{n} / \mathrm{a}$ & No & $\mathrm{n} / \mathrm{a}^{\mathrm{TT}}$ & 6 \\
\hline 6 & Heartmate II & 218 & 30 & 0.45 & Intermed & Y & $\mathrm{n} / \mathrm{a}$ & No & 9 & 8 \\
\hline 7 & Heartmate II & 42 & 16 & 0.63 & Low & Y & $(-)$ & $\begin{array}{l}\text { DVT, PE, } \\
\text { stroke }\end{array}$ & 13 & $1^{t}$ \\
\hline 8 & Heartmate ॥ & 526 & 45 & 3.15 & High & Y & $(+)$ & $P E$ & 5 & 5 \\
\hline
\end{tabular}

*Temporal Plt Nadir = Plt count nearest (within 24 hr) of HIT antibody + .

**4-T probability: High-probability 6-8 points, intermediate probability $4-5$ points, low probability $\leq 3$ points.

***SRA is a send out laboratory assay at our institution with a typical turn-around time of 3-5 days.

${ }^{T}$ HITTS $=$ diagnosed thrombosis at the time of HIT antibody + .

"Data unavailable regarding preadmission or outside facility heparin exposure for any patient (eg. cardiac catheterization).

${ }^{\Pi \pi}$ First known exposure to heparin was intraoperative.

${ }^{\text {t}}$ Patient developed + HIT antibody on a subsequent admission after initial admission for LVAD surgery.

HIT = heparin-induced thrombocytopenia.

LVAD = left-ventricular-assist device.

$\mathrm{PIt}=$ platelet

$\mathrm{OD}=$ optical density.

SRA = serotonin release assay

HITTS = heparin-induced thrombotic and thrombocytopenic syndrome at time of HIT antibody + . 
Table 2 Treatment characteristics

\begin{tabular}{|c|c|c|c|c|c|c|c|}
\hline Patient & CKD & $\begin{array}{c}\text { Fondaparinux } \\
\text { dose }\end{array}$ & $\begin{array}{c}\text { Duration of } \\
\text { fondaparinux (days) }\end{array}$ & $\begin{array}{c}\text { Transitioned and discharged } \\
\text { on warfarin }(\mathrm{Y} / \mathrm{N})\end{array}$ & $\begin{array}{c}\text { Concurrent } \\
\text { aspirin dosage }\end{array}$ & $\begin{array}{c}\text { New thrombosis } \\
\text { after fondaparinux* }\end{array}$ & $\begin{array}{c}\text { Major bleeding } \\
\text { after fondaparinux }\end{array}$ \\
\hline 1 & Y & $2.5 \mathrm{mg}$ & 5 & Y & $81 \mathrm{mg}$ & No & No \\
\hline 2 & N & $2.5 \mathrm{mg}$ & 22 & N & $81 \mathrm{mg}$ & LVAD thrombosis & No \\
\hline 3 & N & $5 \mathrm{mg}$ & 14 & Y & $325 \mathrm{mg}$ & No & No \\
\hline 4 & N & $5 \mathrm{mg}$ & 4 & Y & $325 \mathrm{mg}$ & No & No \\
\hline 5 & N & $5 \mathrm{mg}$ & 3 & Y & $81 \mathrm{mg}$ & $P E$ & No \\
\hline 6 & N & $7.5 \mathrm{mg}$ & 10 & Y & $81 \mathrm{mg}$ & DVT & Overt bleed** \\
\hline 7 & N & $7.5 \mathrm{mg}$ & 3 & N & $81 \mathrm{mg}$ & No & Blood transfusion $* * *$ \\
\hline 8 & Y & $10 \mathrm{mg}$ & 2 & Y & $81 \mathrm{mg}$ & No & Blood transfusion*** \\
\hline
\end{tabular}

*All thrombotic events occurred prior to discharge on the admission in which HIT was diagnosed.

**Overt bleeding $=\geq 2$ gram $\mathrm{g} / \mathrm{dL}$ decrease in any $24 \mathrm{hr}$ period.

***Believed to be related to clinical course and unrelated to anticoagulation therapy.

$\mathrm{CKD}=$ chronic kidney disease; defined as estimated glomerular filtration rate $(G F R)<60 \mathrm{~mL} / \mathrm{min} / 1.73 \mathrm{~m} 2$ for $>3$ months.

$\mathrm{DVT}=$ deep vein thrombosis.

$\mathrm{PE}=$ pulmonary embolism.

patients that developed a new thrombotic event while receiving fondaparinux presented with iHIT at time of HIT diagnosis. There were no bleeding events into any critical organs and no fatal bleeding. One overt bleeding event was reported, but did not warrant cessation of anticoagulation or red blood cell transfusion. Two (25\%) patients required red blood cell transfusion after the initiation of fondaparinux though the need for transfusion was not believed to be related to anticoagulation therapy. In the two patients that required transfusion, the admission hemoglobin $(\mathrm{Hgb})$ was 12.4 and $15 \mathrm{mg} / \mathrm{dL}$ with a nadir Hgb 6.7 and $8.6 \mathrm{mg} / \mathrm{dL}$ and average Hgb throughout admission of 9.4 and $10.2 \mathrm{mg} / \mathrm{dL}$, respectively. Each patient only required one transfusion. No patients died or were discharged to hospice and all patients were successfully discharged home or to rehabilitation.

\section{Discussion}

In our evaluation we experienced only one major bleeding episode with the use of fondaparinux for confirmed or suspected HIT. Given the lack of major bleeding complications, it appears that fondaparinux could be a safe option for the treatment of HIT in LVAD patients. It is of special importance to find safe alternative anticoagulants for the treatment of HIT in a patient population that is already predisposed to bleeding. Post-cardiac surgery patients are at an increased risk of bleeding due to both surgical and non-surgical causes. Approximately 20\% of post-cardiac surgery patients bleed significantly due to surgical bleeding [25]. These patients are also at risk for bleeding because of undergoing cardiopulmonary bypass $(\mathrm{CPB})$. Cardiopulmonary bypass can increase bleeding due to exposure of procedural high dose anticoagulation (eg. heparin), extensive surgical trauma, prolonged exposure of blood to an artificial surface leading to reactant activation of thrombolysis and fibrinolysis, as well as significant platelet dysfunction from a CPB-induced loss of receptors for von Willebrand factor (GP1b) and fibrinogen (GP2b3a) [26]. Beyond that, patients with continuous flow LVAD have been shown to develop a relative von Willebrand factor deficiency which is hypothesized to contribute to the bleeding incidences in this population [27]. Because we observed minimal bleeding in light of these risks, this agent may prove to be safe for this patient population.

There is concern for efficacy in this small sample size due to 3 of the 8 patients developing new thrombotic events following initiation of fondaparinux after HIT diagnosis. Data with FDA approved DTI's, (lepirudin and argatroban) have demonstrated new thromboses from HIT after initiation of alternative anticoagulation at lower rates in other patient populations $(6-10 \%$ and $13-19 \%$ of patients respectively) [28-34]. Comparison between this historical data and our evaluation must be made with caution because the post-cardiac surgery LVAD patient population carries a significant risk of clotting that others may not. It has been demonstrated that patients requiring CPB have a high expression of tissue factor (TF) and activated factor VII (fVIIa) due to direct contact with the CPB-circuit $[27,35]$. This expression leads to the activation of the contact coagulation pathway as well as activation of the intrinsic coagulation pathway leading to thrombin generation. Beyond that, patients that undergo CPB develop systemic inflammation [27]. Through acute-phase inflammatory reactants such as leukocytes, interleukin 1 , tumor necrosis factor, and endotoxin, TF expression is increased on the endothelium leading to further activation of the coagulation pathways [27]. Further, LVAD patients are known to be at a high risk for thrombosis. Recent evaluation has shown fibrin deposition as a possible culprit leading to hemolysis, increase in shear stress, and pump thrombosis [36]. Because of these factors, comparisons with historical data are confounded because significant 
thrombotic risks exist in the post-cardiopulmonary bypass LVAD population.

Because fondaparinux has not been systematically studied in this population for this indication, it is unknown if the thrombotic observations noted were dose related and if efficacy could be optimized using different dosing strategies. It is important to note, that based on current treatment recommendations for acute DVT/PE, only 3 of the 8 patients evaluated received appropriate weight-based doses [22]. Of the three patients that developed thrombosis after initiation of fondaparinux, only 1 of them was on the appropriate weight-based dose (data not shown). There is recommendation for dose reduction in renal dysfunction, but renal function data was not collected and thus appropriateness of dosing cannot be fully evaluated. Because post-operative LVAD patients often develop varying degrees of renal insufficiency, there is likelihood that dose modification based on renal function was present. Without this information, this is only speculation. Further, during the observation period and to date there are not recommendations for routine utilization of anti-Xa serum concentrations to assess fondaparinux efficacy. If this information were available in our analysis, firmer conclusions could be made regarding the efficacy of the current doses in relation to our thrombotic observations. Also, given the retrospective nature of this evaluation, it is difficult to determine if thrombotic variables we observed were related to HIT, its treatment, or to the clinical course of LVAD therapy.

Confounding our observations further, it appears that in our evaluation there is potential for a high number of false positive HIPA tests. Because the 4-T pre-test probability demonstrated mostly low and intermediate probability with only one patient with high probability and only one patient ELISA OD value greater than 1, it is possible we were treating false-positive HIT antibodies $[24,29]$. It has been shown that patients with an ELISA OD less than 1 only had a $3.4 \%$ positive diagnosis for HIT, an OD 1-2 demonstrated $45.5 \%$ positive diagnosis, and greater than 2 with $78 \%$ positive diagnosis [37]. Of note, the 4-T pre-test probability was calculated retrospectively and thus this information was not explicitly found in the medical record or stated as available for the treating clinicians. It has been found previously that there are a large number of false positive HIT antibodies in post-cardiac surgery patients and that often a low platelet count remains so for non-HIT reasons [38-40]. These patients develop a consumptive thrombocytopenia from cardiopulmonary bypass required during LVAD implantation which also has been shown to release platelet factor 4 which could lead to false positivity with ELISA testing [41]. It is also important to point out that only $50 \%$ of the patients in our analysis had confirmatory testing sent (Table 1) and without confirmatory testing, it is difficult to know if we are treating true HIT.
There are numerous characteristics which would make fondaparinux an attractive agent in this high-bleeding/ high-thrombotic risk population. First, it has a lower burden of therapy. One could hypothesize that treatment with fondaparinux is easier than continuous infusion DTI's given it is administered once daily with minimal required monitoring parameters and does not require intravenous access. Also, fondaparinux potentially allows for an easier transition to warfarin than argatroban as it has no significant effect on the INR which is desirable as LVAD patients have indications for warfarin therapy beyond HIT itself [41]. Because it is distributed in the blood, changes that occur in LVAD patients' volume status post-operatively are not likely to affect the pharmacokinetics and pharmacodynamics of this medication. Also, it does not need or undergo hepatic biotransformation which may allow for utilization in patients that would otherwise be challenging with argatroban. Though it does require dose modification for renal dysfunction, more data is emerging on how to optimize this medication in this patient subset [41]. Lastly, in terms of safety, the major bleeding rates of fondaparinux when utilized for HIT appear very low especially in comparison to the bleeding rates with DTI's which would be of potential benefit in a patient group at high risk for bleeding complications such as LVAD patients, but without head-to-head comparator trials, this conclusion cannot be confirmed [19,31-33]. All of these attractive characteristics would have to be balanced with the potential concerns for efficacy seen in our observations but prospective or large retrospective comparator trials would be warranted to attempt to elucidate this information.

\section{Conclusions}

Given the low incidence of major bleeding complications with therapy, fondaparinux may be a useful agent in a high-bleeding-risk population, such as LVAD patients, for the treatment of HIT. Based on our observations, concern for efficacy exists, especially in this highly thrombogenic patient population. Prospective, multi-center or large registry comparator evaluations are necessary to further investigate this question.

\footnotetext{
Abbreviations

VAD: Ventricular assist device; LVAD: Left ventricular assist device; INR: International normalized ratio; HIT: Heparin-induced thrombocytopenia; DTI: Direct thrombin inhibitor; OD: Optical density; ELISA: Enzyme-linked immunosorbent assay; HIPA: Heparin-induced platelet antibody; EMR: Electronic medical record; PRBC: Packed red blood cell; iHIT: Isolated heparin-induced thrombocytopenia; HITTS: Heparin-induced thrombocytopenia and thrombotic syndrome; IQR: Interquartile range; CKD: Chronic kidney disease:

GFR: Glomerular filtration rate; ICU: Intensive care unit; SRA: Serotonin release assay; DVT: Deep vein thrombosis; PE: Pulmonary embolism; Hgb: Hemoglobin; CPB: Cardiopulmonary bypass; FDA: Food and drug administration; TF: Tissue factor; fVlla: Activated factor seven.
}

Competing interests

The authors declare that they have no competing interests. 


\section{Authors' contributions}

SB conceived the investigation, was responsible for evaluation coordination, IRB submission, over-seeing data collection, and manuscript composition. SD, NT, AS and TT participated in evaluation strategy, data collection, and manuscript composition. All authors read and approved the final manuscript.

\section{Author details}

${ }^{1}$ Department of Pharmacy, The University of Chicago Medicine, $5841 \mathrm{~S}$. Maryland Ave. TE026, MC0010, Chicago, IL 60637, USA. ²Department of Clinical Sciences, Roosevelt University College of Pharmacy, Schaumburg, IL, USA

Received: 18 October 2013 Accepted: 17 March 2014

Published: 21 March 2014

\section{References}

1. Friedrich EB, Bohm M: Management of end stage heart failure. Heart 2007, 93(5):626-631

2. Miller LW: Is left ventricular assist device therapy underutilized in the treatment of heart failure? Circulation 2011, 123:1552-1558.

3. Cleveland JC Jr, Naftel DC, Reece TB, Murray M, Antaki J, Pagani FD, Kirklin IK: Survival after biventricular assist device implantation: analysis of interagency registry for mechanically assisted circulatory support database. J Heart Lung Transplant 2011, 30:862-869.

4. Wu L, Weng YG, Dong NG, Krabatsch T, Stepanenko A, Hennig E, Hetzer R: Outcomes of the HeartWare ventricular assist system support in 141 patients: a single-centre experience. Euro J of CT Surg 2013, 44:139-145.

5. Dell'Aquila AM, Schneider SR, Schlarb D, Redwan B, Sindermann JR, Ellger B, Stypmann J, Tjan TD, Scheld HH, Hoffmeier A: Initial clinical experience with the HeartWare left ventricular assist system: a single-center report. Ann Thorac Surg 2013, 95(1):170-177.

6. Park SJ, Milano CA, Tatooles AJ, Rogers JG, Adamson RM, Steidley DE, Ewald GA, Sundareswaran KS, Farrar DJ, Slaughter MS, HeartMate II Clinical Investigators: Outcomes in advanced heart failure patients with left ventricular assist devices for destination therapy. Circ Heart Fail 2012, 5(2):241-248.

7. Barnes K: Complications in patients with ventricular assist devices Dimens Crit Care Nurs 2008, 27(6):233-241.

8. Kroekel PA, George L, Eltoukhy N: How to manage the patient in the emergency department with a left ventricular assist device. J Emerg Nursing 2012, 1(7):1010-1016.

9. Schaffer JM, Arnaoutakis GJ, Allen JG, Weiss ES, Patel ND, Russell SD, Shah AS, Conte JV: Bleeding complications and blood product utilization with left ventricular assist device implantation. Ann Thorac Surg 2011, 91(3):740-747

10. Mehra MR, Griffith BP: Assisted circulation in the treatment of heart failure Bonow: Braunwald's heart disease - a textbook of cardiovascular medicine. 9th edition. Philadelphia, PA: El Sevier Inc; 2012:617-626.

11. Kurlen $S$, Hughes KA: Anticoagulation and bleeding in patients with ventricular assist devices walking the tightrope. AACN Adv Crit Care 2012, 23(1):91

12. Feldman D, Pamboukian SV, Teutuberg JJ, Birks E, Lietz K, Moore SA, Morgan JA, Arabia F, Bauman ME, Buchholz HW, Deng M, Dickstein ML, El-Banayosy A, Elliot T, Goldstein DJ, Grady KL, Jones K, Hryniewicz K, John R, Kaan A, Kusne S, Loebe M, Massicotte MP, Moazami N, Mohacsi P, Mooney M, Nelson T, Pagani F, Perry W, Potapov EV, Eduardo Rame J, et al: The 2013 international society for heart and lung transplantation guidelines for mechanical circulatory support: executive summary. $J$ of Heart and Lung Transplant 2013, 32:157-187.

13. Warkentin TE, Greinacher A, Koster A: Heparin induced thrombocytopenia in patients with VAD; are new prevention strategies required? Ann Thorac Surg 2009, 87(5):1633-1640.

14. Warkentin TE, Greinacher A, Koster A, Lincoff AM: Treatment and prevention of heparin induced thrombocytopenia: American college of chest physicians evidence-based clinical practice guidelines (8th edition). Chest 2008, 133(6 Suppl):340S-380S

15. Pappalardo F, Scandroglio AM, Potapov E, Stepanenko A, Maj G, Krabatsch T, Zangrillo A, Koster A, Hetzer R: Argatroban anticoagulation for heparin induced thrombocytopenia in patients with ventricular assist devices. Minerva Anestesiol 2012, 78(3):330-335.
16. Czosnowski QA, Finks SW, Rogers KC: Bivalirudin for patients with heparin-induced thrombocytopenia undergoing cardiovascular surgery. Ann Pharmacother 2008, 42(9):1304-1309.

17. Koster A, Weng Y, Böttcher W, Gromann T, Kuppe H, Hetzer R: Successful use of bivalirudin as anticoagulant for ECMO in patient with acute HIT. Ann Thorac Surg 2007, 83:1865-1867.

18. Rutledge JM, Chakravarti S, Massicotte MP, Buchholz H, Ross DB, Joashi U: Antithrombotic strategies in children receiving long-term Berlin heart EXCOR ventricular assist device therapy. J Heart Lung Transplant 2013, 32(5):569-573.

19. Warkentin TE, Pai M, Sheppard JI, Schulman S, Spyropoulos AC, Eikelboom JW: Fondaparinux treatment of acute heparin induced thrombocytopenia confirmed by the serotonin-releaseassay: a 30-month, 16-patient case series. J Thromb Haemost 2011, 9(12):2389-2396.

20. Corbett TL, Elher KS, Garwood CL: Successful use of fondaparinux in a patient with a mechanical heart valve replacement and a history of heparin-induced thrombocytopenia. J Thromb Thrombolysis 2010 30(3):375-377

21. Gellatly RM, Leet A, Brown KE: Fondaparinux: an effective bridging strategy in heparin-induced thrombocytopenia and mechanical circulatory support. J Heart Lung Transplant 2013. S1053-2498(13)01355-7. doi: 10.1016/j.healun.2013.07.015. [Epub ahead of print].

22. Information P: ARIXTRA (R) subcutaneous injection, fondaparinux sodium subcutaneous injection. Research Triangle Park, NC: GlaxoSmithKline; 2008.

23. Cuker A, Cines DB: How I treat heparin-induced thrombocytopenia. Blood 2012, 119(10):2209-2218

24. Lo GK, Juhl D, Warkentin TE, Sigouin CS, Eichler P, Greinacher A Evaluation of pretest clinical score (4 T's) for the diagnosis of heparin-induced thrombocytopenia in two clinical settings. J Thromb Haemost 2006, 4:759-765.

25. Moulton MJ, Creswell LL, Mackey ME, Cox JL, Rosenbloom M: Re-exploration for bleeding is a risk factor for adverse outcome after cardiac operations. J Thoracic Cardiovasc Surg 1996, 110:1037-1046

26. Paparella D, Brister SJ, Buchanan MR: Coagulation disorders of cardiopulmonary bypass: a review. Intensive Care Med 2004, 30(10):1873-1881.

27. Crow S, Chen D, Milano C, Thomas W, Joyce L, Piacentino V 3rd: Acquired von Willebrand syndrome in continuous-flow ventricular assist device recipients. Ann Thorac Surg 2010, 90:1263-1269.

28. Greinacher A, Janssens U, Berg G, Böck M, Kwasny H, Kemkes-Matthes B, Eichler P, Völpel H, Pötzsch B, Luz M: Lepirudin (recombinant hirudin) for parenteral anticoagulation in patients with heparin-induced thrombocytopenia. Circulation 1999, 100:587-593.

29. Greinacher A, Eichler P, Lubenow N, Kwasny H, Luz M: Heparin induced thrombocytopenia with thromboembolic complications: meta-analysis of 2 prospective trials to assess the value of parenteral treatment with lepirudin and its therapeutic aPTT range. Blood 2000, 96:846-851.

30. Eichler $P$, Lubenow N, Greinacher $A$ : Results of the third prospective study of treatment with lepirudin in patients with heparin-induced thrombocytopenia (HAT) [abstract]. Blood 2002, 100(1):704a.

31. Lubenow N, Eichler $P$, Greinacher A: Results of a large drug monitoring program confirms the safety and efficacy of refludan (Lepirudin) in patients with immune-mediated heparin-induced thrombocytopenia [abstract]. Blood 2002, 100(1):502a.

32. Lewis BE, Wallis DE, Berkowitz SD, Matthai WH, Fareed J, Walenga JM, Bartholomew J, Sham R, Lerner RG, Rustagi PK, Jang IK, Rifkin SD, Moran J, Hursting MJ, Kelton JG, ARG-911 Study Investigators: Argatroban anticoagulant therapy in patients with heparin-induced thrombocytopenia. Circulation 2001, 103:1838-1843.

33. Lewis BE, Wallis DE, Leya F, Hursting MJ, Kelton JG, Argatroban-915 Investigators: Argatroban anticoagulation in patients with heparin-induced thrombocytopenia. Arch Intern Med 2003, 163:1849-1856.

34. Warkentin TE, Sheppard JI, Moore JC, Sigouin CS, Kelton JG, Sigouin CS, Kelton JG: Quantitative interpretation of optical density measurements using PF4-dependent enzyme-immunoassays. J Thromb Haemost 2008, 6:1304-1312.

35. Chung JH, Gikakis N, Rao AK, Drake TA, Colman RW, Edmunds LH Jr: Pericardial blood activated the extrinsic coagulation pathway during clinical cardiopulmonary bypass. Circulation 1996, 93:2014-2018.

36. Starlin RC, Moazami N, Silvestry SC, Ewald G, Rogers JG, Milano CA, Rame JE, Acker MA, Blackstone EH, Ehrlinger J, Thuita L, Mountis MM, Soltesz EG, Soltesz EG, Lytle BW, Lytle BW, Smedira NG: Unexpected abrupt increase in left ventricular assist device thrombosis. NEJM 2014, 370:33-40. 
37. Pearson MA, Nadeau C, Blais N: Correlation of optical density with clinical diagnosis of heparin-induced thrombocytopenia: a retrospective study of 104 patients with positive anti-PF4/heparin ELISA. Clin Appl Thromb Hemost 2013. Nov 27 [epub].

38. Selleng S, Selleng K, Wollert HG, Muellejans B, Lietz T, Warkentin TE, Greinacher A: Heparin-induced thrombocytopenia in patients requiring prolonged intensive care unit treatment after cardiopulmonary bypass. J Thromb Haemost 2008, 6(3):428-435.

39. Warkentin TE: How I diagnose and manage HIT. Hematology Am Soc Hematol Educ Program 2011, 2011(1):143-149.

40. Warkentin TE: Agents for the treatment of heparin-induced thrombocytopenia. Hematol Oncol Clin North Am 2010, 24(4):755-775.

41. Garcia DA, Baglin TP, Weitz JI, Samama MM, American College of Chest Physicians: Parenteral anticoagulants: antithrombotic therapy and prevention of thrombosis, 9th ed: American college of chest physicians evidence-based clinical practice guidelines. Chest 2012, 141(2 Suppl):24-43.

doi:10.1186/1749-8090-9-55

Cite this article as: Benken et al:: A retrospective evaluation of fondaparinux for confirmed or suspected heparin-induced thrombocytopenia in left-ventricular-assist device patients. Journal of Cardiothoracic Surgery 2014 9:55.

\section{Submit your next manuscript to BioMed Central and take full advantage of:}

- Convenient online submission

- Thorough peer review

- No space constraints or color figure charges

- Immediate publication on acceptance

- Inclusion in PubMed, CAS, Scopus and Google Scholar

- Research which is freely available for redistribution 